\title{
Minutes of the Spring 2021 Council Meeting
}

April 30, 2021, APSA Council Meeting

\section{PRESENT}

Janet Box-Steffensmeier, Ohio State University, President

Paula McClain, Duke University, Past-President

John Ishiyama, University of North Texas, President-Elect

Michelle Deardorff, University of Tennessee at Chattanoo-

ga, Vice President

Mala Htun, University of New Mexico, Vice President

John Sides, Vanderbilt University, Vice President

David Lublin, American University, Treasurer

Ben Ansell, University of Oxford; Adam Berinsky, Massachusetts Institute of Technology; Erik Bleich, Middlebury College; Ann O'M. Bowman, Texas A\&M University; Menna Demessie, Task Force for Meaningful Change, Universal Music Group; Catherine Guisan, University of Minnesota; Rebecca Gill, University of Nevada, Las Vegas; Terri Gilmour, Midland College; Nancy Hirschmann, University of Pennsylvania; Nahomi Ichino, Emory University; Julia Jordan-Zachery, University of North Carolina at Charlotte; Sooyeon Kim, National University of Singapore; David Leal, University of Texas at Austin; Suzanna Linn, Pennsylvania State University; Lori Marso, Union College; Tamara Metz, Reed College; Ido Oren, University of Florida; Melanye Price, Prairie View A\&M University; Charles "Tony" Smith, University of California, Irvine; Rocio Titiunik, Princeton University; Lisa Wedeen, University of Chicago

\section{APSA STAFF}

Steven Rathgeb Smith, Betsy Super, Dan Gibson, Kimberly Mealy, Nathaniel Bader, Larry Burner, Jon Gurstelle, Casey Harrigan, Meghan McConaughey, Abby Paulson, Andrew Stinson, Ashley Vande Bunte

\section{INTRODUCTION}

APSA President Janet Box-Steffensmeier calls the 2021 APSA Spring Council Meeting to order.

\section{CONSENT AGENDA}

Box-Steffensmeier introduces the 2020 APSA Fall Council Meeting minutes for approval. Deardorff moves to approve the minutes; the motion is seconded by Linn and passes unanimously. Box-Steffensmeier introduces the 2020 APSA December Council Meeting minutes for approval. Linn moves to approve the minutes; the motion is seconded by Berinksy and passes unanimously.

\section{PRESIDENT'S REPORT}

Box-Steffensmeier provides an update to Council on recent association activities and accomplishments. She begins her report by thanking the APSA staff, the Council, and the membership for their work in advancing the work of the discipline during the COVID-19 pandemic, particularly the work of community college faculty in providing resources for virtual teaching and learning. She notes that the presidential task force will result in an edited volume focusing on methodological pluralism. She recognizes the leadership of APSA in diversity, equity, and inclusion, especially over the past year. Finally, she notes APSA's progress on public and civic engagement.

\section{TREASURER'S REPORT}

On behalf of Treasurer David Lublin, APSA Executive Director Steven Rathgeb Smith introduces the treasurer's report to update the Council on the Association's financial position. S. Smith reports that APSA continues to operate in sound financial shape, especially as the strong stock market has provided significant returns. He reports that APSA still faces financial uncertainty due to a decline in traditional sources of revenue such as membership, rental income, sponsorship money, and the Annual Meeting. As of March 31, 2021, the total fair market value of all APSA investments was $\$ 48$ million, with the most significant investment groups being the Congressional Fellowship Program trust portfolio and the Trust and Development portfolio. In addition, the Working Capital fund, which totaled \$2.3 million was folded into the two primary investment accounts according to the current investment allocation policy. S. Smith reports that the Investment Committee approved moving more than 95 percent of investments from mutual index funds to environmental, social, and governance (ESG) funds. The outstanding funds will remain as mutual index funds because no ESG analog exists for those funds. He notes that ESG risk and return is in line with the risk and return of mutual index funds. S. Smith reports that APSA received a $\$ 450,000$ loan from the Paycheck Protection Program in 2020 and has applied for the loan to be converted to a grant since APSA did not lay off any staff member. He further reports that APSA received a $\$ 286,000$ insurance payout relating to the cancellation of the in-person portion of the 2020 Annual Meeting. $\mathrm{He}$ also notes that the APSA headquarters building in Washington, D.C. is being renovated. Finally, he notes that, as of January 1, 2021, APSA has updated its fiscal year to coincide with the calendar year.

\section{EXECUTIVE DIRECTOR'S REPORT}

S. Smith introduces updates on association programming and operations to provide information to the Council. S. Smith begins the report by remarking on the unprecedented topics in the prior year such as a global pandemic, a renewed focus on social justice, economic and social challenges faced by members, and financial cutbacks in higher education that have affected how APSA conducts operations and responds to the needs of the membership. S. Smith notes that some of these adaptations include remote work by APSA staff, a fully virtual Annual Meeting in September 2020, changing expectations and responses for APSA assistance and guidance during the pandemic, and a more focused commitment to addressing systemic racism. He reports that APSA has placed an emphasis on supporting members via various programs, including member relief grants, the member rebate program, and greater flexibility in Centennial Center grants and Diversity Fellowship Travel Grants, increased support for Accessibility Grants for the Annual Meeting, greater support for the participants of the 2020 alternative Ralph Bunche Summer Institute (RBSI) programming hosted by APSA and the 2021 virtual RBSI, and a Presidential Task Force on the Coronavirus.

S. Smith reports that, due to the effects of the pandemic on members and institutions, total membership has decreased by approximately 10 percent as compared to pre-pandemic levels. He notes that a greater percentage of members are opting for the multi-year 
membership option, with multi-year memberships now comprising 19 percent of eligible members. Further, he reports that 67 percent of regular members and 69 percent of student members belong to at least one organized section, and that joining an organized section contributes toward a greater retention rate among new members. He notes that organized sections that have waived fees for students have experienced a growth in membership. He reports that 26 of the 45 related groups have met the 35-member minimum threshold, and the remaining 19 related groups are receiving guidance and assistance to meet that threshold.

Next, S. Smith reports that diversity and inclusion, a top priority of APSA, has continued existing programming and begun new efforts over the past year. He reports that Diversity and Inclusion Advancing Research Grants, which launched in fall 2020, awarded seven grants totaling \$15,500, and that a new initiative, Research Advancement for Indigenous Politics, will support six grants. He notes that resources about addressing systemic racism, social justice, and anti-Asian violence appear on the APSA website. Further, he notes that APSA staff have updated member data to include tags for faculty and students at minority serving institutions.

S. Smith continues by reporting select program highlights. He begins by noting the success of APSA Educate, APSA's major online resource for teaching and learning, in providing resources for online and hybrid teaching formats. He continues by commenting on the launch of the new member magazine Political Science Today and editorial searches for PS: Political Science and Politics and Journal of Political Science Education. He reports that APSA awarded 23 Doctoral Dissertation Research Improvement Grants. Next, he reports on a series of new initiatives, including the launch of the Career Diversity Committee in December 2020, a new department newsletter, and new webinars covering a variety of topics on teaching and learning. He concludes program highlights by recognizing that despite being held virtually in 2020 and into 2021, the MENA (Middle East and North Africa) and Asia Workshops continue to have very high demand. S. Smith notes that the effects of the pandemic have necessitated innovation and created new opportunities to serve members and provide value and resources to the discipline.

Guisan asks if the 10 percent decline in membership is because of the effects of the pandemic or another factor. S. Smith replies that membership may have declined due to pandemic-associated reductions or freezes in research funds, travel funds, or salaries. He notes that membership is indirectly associated with the Annual Meeting, so the virtual Annual Meeting in 2020 may have influenced membership. Box-Steffensmeier notes that non-academic member outreach would increase the membership and benefit the discipline. S. Smith reports that APSA is reviewing the value proposition for membership, especially in virtual settings. Leal asks what peer associations are doing to increase the value proposition for members. S. Smith replies that some peer associations offer forms of insurance to members. Super adds that many peer associations have placed an emphasis on webinars. She notes that APSA is also doing webinars, but those efforts were initially secondary to the innovation and time spent on holding a fully virtual Annual Meeting. S. Smith notes that it is difficult to convert webinar participation into membership.

\section{MEMBER REVOCATION POLICY DISCUSSION}

Box-Steffensmeier introduces a discussion on the draft member revocation policy. Super begins the discussion by providing a background and overview of the draft revocation policy, which is meant to cover a limited number of egregious cases. She notes that the draft policy was formulated in consultation with the chairs of the Ethics Committee and the Membership and Professional Development Policy Committee and was reviewed by the Ethics Committee, the Membership and Professional Development Policy Committee, and APSA legal counsel. She reports that this policy provides for a method to address findings of ethical misconduct that have come as a result of other organizations' investigative processes such as Title IX, public court records, other association findings. Super notes that this policy would supplement APSA's anti-harassment policy and Ethics Guide. The draft policy details an initial review by APSA Executive Office staff, who would be identified as reviewers on the APSA website, before any valid claims move to a revocation panel. The panel would make a recommendation, based on majority vote, on whether to revoke membership, leadership, and attendance privileges. If a recommendation to revoke is made, the case moves to the Council for a vote, which, according to existing bylaws, can vote with a $2 / 3$ rds majority vote to revoke membership, leadership, and attendance privileges of the person in question for a period of years. The draft policy further outlines the possibility of rehabilitation, restorative justice, or overturning the decision in light of new information. Super notes that for its first year, the draft policy does not cover accusations of plagiarism. Additionally, she notes that there is a high bar placed on corroborating evidence and a possible difference in the ability to obtain documentation from public and private institutions. Further, she notes that the draft policy includes a proviso for a review after two years to ensure the policy is functioning as intended. Price reports the views of the Membership and Professional Development Committee. She notes that the committee expressed the need for the draft policy to fit into the framework of the Ethics Guide and anti-harassment policy. She also reports that a high bar of evidence should be placed on member revocation, but the bar should not be so high as to become impossible to obtain such corroborating documentation or materials.

Ansell and Gill inquire about the role of the policy in areas of ethical misconduct as opposed to more recognized forms of academic or professional misconduct. Super replies that the draft policy does not address academic misconduct such as plagiarism as other institutional findings are rare in those cases; however, academic and professional misconduct as it pertains to the draft policy may be evalvated at the two-year review. Mealy notes that peer associations are also drafting similar policies. Sides asks if the draft revocation policy would prohibit a sanctioned individual from publishing in an APSA journal. After Super replies that it does not, several Council members voice support for the draft policy to bar a sanctioned individual from publishing in an APSA journal. Htun and Ansell express concern about barring a sanctioned individual from publishing in an APSA journal, with Ansell noting his concern is because it could negatively affect co-authors. Ishiyama notes that restricting the ability of an individual to publish in an APSA journal would alter the relationship between APSA and the journals. Several Council members voice support for asking the relevant committees to discuss the draft policy in relation to APSA journals. Titiunik asks about what types of information may be accepted as corroborating documentation and if the bar for evidence is too high. Super replies that there is discretion of what information may be used to decide to bring a case forward or to revoke member privileges. Box-Steffensmeier adds that there will be misconduct that will not be addressed by the policy, but it is intended to provide consequences for the most egregious behavior. Oren and Gill note that there are multiple review levels and a possibility to hear evidence as well as hear from the accused before moving toward possible revocation. Deardorff expresses concern that there 
may not be enough evidence to permit any form of action by APSA. Htun notes that APSA would not be conducting an investigation but would be evaluating the totality of external findings. She further expresses support for the rehabilitation and restorative justice provisions in the draft policy. Kim asks about the possibility of an individual suing APSA for unfair revocation. Super notes that the risk is low, but it is a possibility. She notes that the risk of legal challenges was kept in mind throughout the development of the policy. Price moves to adopt the member revocation policy; Oren seconds and the motion is approved unanimously.

\section{MCCLAIN PRESIDENTIAL TASK FORCE}

McClain introduces an update on the McClain Presidential Task Force. She begins by thanking Mealy and the four task force cochairs. She reports that there are approximately 35 scholars working on the task force in various capacities. She notes that the task force will present its findings to the discipline at the 2021 Annual Meeting. Price asks if there will be recommendations for implementation. McClain replies that the report will contain accounting as well as recommendations and best practices that can help move the discipline in a better direction that is more inclusive for all members. Htun asks if there are plans for outreach and dissemination. McClain replies that there is not a communications strategy yet, but the plan is to work with APSA staff to determine a communication strategy once the report is finalized.

\section{ISHIYAMA PRESIDENTIAL TASK FORCE AND THEME STATEMENT}

Ishiyama introduces an update on the Ishiyama Presidential Task Force and the theme statement for the 2022 Annual Meeting in Montreal. He notes that the co-chairs are Pei-te Lien, University of California, Santa Barbara and Sherri Wallace, University of Louisville and that the working theme statement for the 2022 Annual Meeting is "Toward a Post-Pandemic Political Science." He notes the widespread societal disruption of the COVID-19 pandemic and its impacts on the discipline and political science education, while expressing interest in how political science can adapt to a changed, post-pandemic world. He reports that the Ishiyama Presidential Task Force will be "Rethinking Political Science Education." Ishiyama notes that the task force will work on rethinking political science education at all levels from civic education at the K-12 level, to undergraduate political science majors, to PhDs. He expresses a desire to reassess the value of a political science degree, especially as undergraduate and graduate political science scholars facing a changing and uncertain job market. He notes the task force will assess the skills and knowledge that exist among graduates, rethink what political science means, and how to communicate findings to the discipline and the public. Ichino suggests the task force provide guidance on assessments in political science education for individual scholars as well as for departments and programs.

\section{ONLINE ACCESS FOR APSA JOURNALS}

Leal, chair of the Publications Committee, introduces a discussion on online access of APSA journals, particularly if journals should continue to be printed and sent to members, or if APSA should adopt an online-only format. He opens the discussion by noting the trends around print journals: digital scholarship has increased over the past year, some publishers have stopped printing journals, and more people are weary of the environmental impact of print journals. Leal notes that moving to an online-only format may assist in a transition to open access and permit APSA to publish more articles or longer articles in each issue, which would create new opportunities to publish. He reports that article publication fees would be the primary revenue source for open access journals, so an online journal with more articles would permit APSA to recoup a portion of the money that would be lost by a transition toward open access. He notes that APSA has spent approximately $\$ 750,000$ over the past ten years on print journals for members, and, despite a decline in numbers of members who elect to receive print journals, the Publications Committee estimates that $\$ 500,000$ would be spent on print journals in the next ten years. Leal reports that the Publications Policy Committee unanimously recommends that APSA cease print copies of all four journals-American Political Science Review, Perspectives on Politics, PS: Political Science and Politics, and the Journal of Political Science Education-beginning in 2022. He notes that those persons with significant needs for a paper copy would still be able to be accommodated. Gurstelle reports that American graduate students represent the largest percentage of members requesting print journal copies, but that group has responded well to free online access of section journals, so it is assessed they would also respond positively to free online access of APSA journals. Further, Gurstelle notes that Political Science Today will continue to be offered in an environmentally responsible print option.

In response to Htun, Leal notes that a scarcity is imposed by print page counts, but an organic expansion of pages available in an online format can increase publishing opportunities without negatively impacting the quality of the journal. Sides expresses support for a transition to online only access as it provides the ability of journals to innovatively and creatively present research. Htun notes that it is important for scholars to be aware of work across the discipline's subfields. Berinsky expresses support for surveying junior scholars to gather their views on print journals and online access. Sides asks if journal articles could be categorized topically and distributed in the same manner as table of contents alerts. Leal moves to transition all APSA journals to online-only for all members other than those with a significant need for a paper copy beginning in January 2022; the motion is seconded and passes unanimously.

\section{ELECTION ASSISTANCE STANDING COMMITTEE PRO- POSAL}

Box-Steffensmeier introduces a discussion on a proposal to create a standing committee for election assistance, the Election Assistance and Policy (EAP) Standing Committee. She notes that APSA has stood up different iterations of an election assistance task force in almost every general election for the past few cycles. She reports that the EAP Committee would build upon the work of the 2020 Election Assistance Task Force. The Task Force leveraged the expertise and experience of political scientists to support free, fair, and open elections in the United States on November 3, 2020 and thereafter. The Task Force's purpose was to foster broader knowledge and understanding of non-partisan election assistance, including resources on non-partisan voter mobilization organizations, poll worker recruitment, technical aid to election officials implementing new systems, voter registration, the prevention of voter intimidation and disenfranchisement, and an understanding of how political scientists empirically identify and measure voter fraud. She notes that it is the recommendation of the Task Force that to be most effective, it should be a permanent committee and continuously build relationships with existing organizations and efforts within and outside of higher education. Hirschmann moves to create an Election Assistance and Policy 
Standing Committee; Ishiyama seconds and the motion passes with one abstention.

\section{ANNUAL MEETING UPDATE}

Vande Bunte begins an update on the 2021 Annual Meeting to be held in Seattle. She reports that APSA is closely monitoring health and safety guidance from national, state, and local governments. She reports that APSA is looking at platforms to host the virtual sessions. Next, she reports that APSA has worked with hotels to renegotiate room blocks to limit financial risk. She reports that APSA is working with a health and safety event management firm to provide best practices, safety reports, and evaluations. Vande Bunte notes that the health and safety firm walked through the event spaces in Seattle with her. She notes that current health and safety protocols include once-daily health screening app, temperature screenings, frequent cleanings, and social distancing. She notes that data from temperature screenings is not stored. Vande Bunte reports that she is holding monthly calls with event spaces and stakeholders to remain informed on any updated guidance.

Leal asks if it is possible to transition from a virtual presentation to an in-person presentation in the same manner that some in-person presentations can be transitioned to virtual presentations. Vande Bunte replies that it is possible to do so, but she notes that it is possible to participate virtually while on site with rooms set aside for that purpose. In response to a question from Ishiyama, Vande Bunte notes that a pre-recording option will be offered. Guisan and Hirschmann ask if the Council meeting will be held virtually, in-person, or hybrid. S. Smith replies that the Council meeting will be held on the Wednesday immediately preceding the Annual Meeting and that the preference is for an in-person Council meeting that has some accommodations for those members who may not be able to attend in-person. Council takes a poll to determine who, at this point, plans to travel to the Annual Meeting.

\section{MEMBER REBATE IMPLEMENTATION}

Harrigan introduces a discussion on the implementation of the member rebate policy. She reports that the member rebate has been built and tested on the APSA website. She notes that the rebate is a onetime only rebate for all new, returning, and renewing members who are registering for the Annual Meeting or are purchasing a membership; however, the rebate will not be included on other transactions. The rebate will be available to all members through December 31, 2021.

\section{ADVOCACY POLICY DRAFT}

Box-Steffensmeier introduces a discussion on the advocacy policy draft. She notes that the draft policy seeks to ensure that operating procedures align with the association's values and priorities. Further, she notes that APSA can issue a variety of statement types, but the three presidents and executive staff leadership have the discretion to respond to current events. McClain reports that, as leaders, the three presidents support the values of diversity and inclusion and are committed to ensure that actions live up to that commitment. She adds that biases and discrimination have no place in the organization, in the discipline, or in society. Ishiyama notes that it is important to respond to specific events as well as broader trends in society, especially when those events or trends negatively impact the ability of members to function as political scientists, member's research is threatened, or political science research and scholarship can shed light on those events or trends. S. Smith provides background on the advocacy policy. He reports that the current advocacy policy was approved by the Council five years ago. He notes that the draft policy includes modest updates to the advocacy policy and the implementation of an internal strategic screening and review process. S. Smith notes the different types of advocacy outreach that APSA does. He notes that APSA writes letters on behalf of individual scholars, departments and programs, and to policymakers. He notes that APSA issues statements in reaction to US government action in relation to political science, international events, and current events with relevance to APSA's valves. He adds that APSA also signs onto joint statements, urges direct member contact through member action alerts, and directly contacts government relations staff and leadership. S. Smith notes that APSA leadership asks several screening questions for statements and letters. He reports that APSA government relations staff determines if a statement or letter is general outreach or special outreach. If the statement or letter is general outreach, which includes letters on behalf of scholars or departments and reaction to government action relating to funding and legislation, the review process will consist of four steps: the executive director confers with the president on the need for a statement; government relations staff drafts a statement or letter; it is reviewed by the executive director, deputy director, and senior director for diversity and inclusion; and the statement is sent to three presidents for review and approval. If the statement or letter is determined to be special outreach such as a reaction to current events or government action outside of general outreach, the review process will consist of five steps: the executive director confers with the president on the need for a statement; government relations staff drafts a statement or letter; it is reviewed by the executive committee and the Council Diversity, Equity and Inclusion Committee; it is sent to the three presidents for review and approval; if necessary, government relations staff can consult with other stakeholders.

The Council moves into a small group discussion session. Following the conclusion of the small group discussion, each group reports back to the full Council about their discussion. Demessie, on behalf of the first small group, notes that there was a consensus that it is better for APSA to do something than to do nothing at all, although not every topic should be responded to. She adds that it is important to have consistent messaging, even if it is reactive, and that political science scholarship should be brought to bear on relevant topics. On behalf of the second group, Gilmour notes that it is important to have a process that ensures respect, tolerance of differing opinions, and proper limits on which events or trends APSA responds to. Next, Sides reports on behalf of the third group. He reports that the third group raised a series of questions to assist in informing policy and further discussion. The first was to ask about the audience and goal for each statement. The second was to ask if APSA has a unique perspective or contribution and whether political science can inform the discussion. The third was does APSA have the ability to effectively convey the desired message. Sides also raises the question of how the association can engage on topics that APSA or many members believe should be universal values but may be perceived as being political values. Reporting for the fourth group, Jordan-Zachery asks whether APSA is a political organization or a political science organization that encourages the study of politics. She notes that statements and letters can be a way of supporting members. Htun adds that APSA's approach to statements and its approach to diversity, equity, and inclusion are being conflated, leading to differing opinions regarding the use, purpose, and need for statements. Metz, on behalf of group five, notes that the group discussed the role of the audience and the intended effect in determining how and when to issue statements.

Ishiyama notes that no policy can cover every contingency, so 
the leadership, as trustees of the association, are entrusted with the discretion to determine if and how the association may respond to events or trends. McClain adds that a contextual element of peer association responses also contributes to the decisions around if and how APSA may respond. Jordan-Zachery suggests utilizing APSA's existing policies on diversity and inclusion on formulating statements. Price expresses support for how APSA has placed an emphasis on diversity, equity, and inclusion, but she and Berinsky note that not all members may agree with the actions taken in support of that commitment. Htun expresses concern about the broad scope of the screening document. Sides notes that a perspective from the small group discussion was that if APSA is committed to diversity, equity, and inclusion and can bring political science scholarship to bear on those topics, then it is possible that APSA should more proactively release statements on those topics rather than waiting for an event to make the topic relevant. Bleich asks if a more proactive stance would make APSA appear politicized. Oren notes that political science and politics are intertwined. In response to a remark by Ansell, Paulson replies that statements and letters are one of many ways in which APSA can communicate principles and values within the association's broader public affairs strategy. Price notes that Council can make statements because of the position of the Council in leading the association, and Demessie notes that silence as well as action can be perceived as a political act. A motion is made to adopt the updated Advocacy Policy; Price seconds and the motion passes with twenty-one ayes, two nays, and two abstentions.

\section{UPDATE ON ETHICS COMMITTEE REVISIONS TO THE ETHICS GUIDE}

Mealy introduces an update on the Ethics Committee's revisions to the Ethics Guide. She reports that the Ethics Committee is working as a whole committee as well as in working groups to review and revise the Ethics Guide. She notes that the Ethics Committee hopes to have a draft for review by the APSA staff and APSA legal counsel by summer
2021. The expectation is to have a final draft submitted for review by Council during the fall 2021 Council Meeting. Mealy notes that the Ethics Committee is also identifying any gaps in the Ethics Guide, particularly guidelines for online and virtual conduct.

\section{POLICY COMMITTEE UPDATES}

Vande Bunte provides updates on the work of the Meetings and Conferences Policy Committee. She reports that the committee has focused on working with related groups to allow them to reach the 35 -member threshold as well as providing guidance on the 2021 Annual Meeting.

Htun, chair of the Membership and Professional Development Policy Committee, provides updates on the work of the committee. She reports that the committee has focused on the member rebate policy and the member revocation policy.

Leal, chair of the Publications Policy Committee, provides updates on the work of the committee. He reports that the committee has focused on journal format, online access for journals, and open access.

Ansell, chair of the Public Engagement Policy Committee, provides updates on the work of the committee. He reports the committee has continued prior efforts to determine if APSA should issue guidelines for how to consider public engagement as part of the tenure and promotion process. He notes the committee is determining the role and purpose of a new standing committee. Paulson adds that the committee continues to discuss APSA's outreach strategy to members and the public.

C. Smith, member of the Teaching and Learning Policy Committee, provides updates on the work of the committee. He notes the committee is working on targeted videos about working and teaching at historically black colleges and universities. Additionally, the committee is working on maneuvering the Teaching and Learning Conference through the pandemic.

Box-Steffensmeier adjourns the meeting.

\section{THE 2021 ORGANIZED SECTION AWARDS}

\section{SECTION 1 : FEDERALISM \& INTERGOVERNMENTAL RELATIONS}

Martha Derthick Book Award

Conferred for the best book on federalism and intergovernmenta relations published at least 10 years ago that has made a lasting contribution to the study of federalism and intergovernmental relations.

Award Committee: Katrina Kosec (Chair), International Food Policy Research Institute; Jean-Paul Faguet, London School of Economics \& Political Science; Jacob Levy, McGill University Recipient: Jonathan Rodden, Stanford University Title: Hamilton's Paradox: The Promise and Peril of Fiscal Federalism. Cambridge University Press, 2005.

\section{Deil S. Wright Best Paper Award}

Conferred for the best paper in the field of federalism and intergovernmental relations presented at the previous year's annual meeting of the APSA.

Award Committee: Laura Evans (Chair), University of Washington; Julia Payson, New York University; Paula Clerici, Universidad de Buenos Aires
Recipients: Katrina Kosec, International Food Policy Research Institute and Tewodaj Mogues, International Monetary Fund Title: "Decentralization without Democracy." World Politics, 2020.

Daniel Elazar Distinguished Federalism Scholar Award Recognizes distinguished scholarly contributions to the study of federalism and intergovernmental relations.

Award Committee: Phil Rocco (Chair), Marquette University; Imke Harbers, University of Amsterdam; Connor Ewing, University of Missouri

Recipient: Kent Eaton, University of California, Santa Cruz

John Kincaid Best Article Award

Conferred on the author(s) of the best article published in Publius:

The Journal of Federalism in the previous year.

Award Committee: Allyson Benton (Chair), City University of London; Liesbet Hooghe, University of North Carolina; Jake Grumbach, University of Washington

Recipient: R. Kent Weaver, Georgetown University

Title: "Policy Dynamics in Federal Systems." Publius: The Journal of 